\title{
A mediação semiótica da "responsabilidade": um estudo sobre a construção de valores na transição para a vida adulta
}

\author{
Elsa de Mattos* \\ Instituto de Psicologia, Programa de Pós-Graduação em Psicologia, Salvador
}

Resumo: A construção de valores é vista como um processo intensamente dinâmico envolvendo internalização e externalização de significados coletivos, além de ser fundamental para a construção de uma síntese pessoal. 0 presente artigo parte da Psicologia Cultural e da Teoria do Self-Dialógico e propõe que a "responsabilidade" pode ser entendida como um valor, como um campo afetivo semiótico carregado de sentidos. Um estudo de caso ilustra como uma jovem (Jane) navega na cultura coletiva e constrói um novo significado pessoal de si mesma como uma "pessoa responsável". O valor da "responsabilidade" vai sendo integrado ao sistema pessoal de valores da jovem através de continuidades e mudanças nos seus posicionamentos ao longo do tempo e em diferentes espaços, especificamente a família, o trabalho e a religião. Os resultados mostram a dinâmica dos posicionamentos e o surgimento de novas perspectivas para o futuro.

Palavras-chave: responsabilidade, valores, transição para a vida adulta, Teoria do Self Dialógico.

Este artigo explora a centralidade da mediação semiótica na experiência dos jovens, focalizando o movimento por meio do qual eles reconfiguram sua cultura pessoal, seu sentido de si mesmo, e constroem e consolidam um sistema de valores capaz de organizar suas relações com o contexto e, também, direcionar suas ações futuras (Zittoun, 2006; Branco \& Valsiner, 2012). Este artigo consta de três partes. Na primeira, buscaremos desenvolver desde a perspectiva da Psicologia Cultural do Desenvolvimento, uma compreensão dos processos de autorregulação semiótica-dialógica, ressaltando sua natureza fundamental para o desenvolvimento humano e também para a construção dos valores - tais como a "responsabilidade" -, que sustentam a experiência da pessoa ao longo da vida. A segunda parte apresenta um estudo de caso que ilustra como a jovem Jane - ao longo do período que vai dos 16 aos 23 anos de idade - negocia sentidos relevantes em torno da questão da "responsabilidade", que passa a constituir um valor central na orientação de suas ações e de sua trajetória de vida. A terceira parte trata da dinâmica dos processos que estão envolvidos na autorregulação levando à construção hierárquica de valores que orientam a trajetória de vida da jovem.

\section{Uma perspectiva semiótica-dialógica da construção dos valores}

Conforme sugerem Branco e Valsiner (2012), os valore não estão na cultura, eles são a cultura, i.e. a cultura se constitui fundamentalmente a partir de valores. Eles estão em toda parte, mas é difícil nomeá-los e localizá-los com precisão. No entanto, eles ganham relevância quando entram em operação. Isso ocorre porque os valores são

* Endereço para correspondência: e.mattos2@gmail.com signos hipergeneralizados que orientam a conduta humana e localizam-se no nível mais alto da hierarquia de regulação semiótica (Branco \& Valsiner, 2012). Os valores podem ser considerados como crenças carregadas de afeto, associadas com propósitos ou com uma orientação para objetivos (Branco \& Madureira, 2008). Branco (2012) ressalta que tal concepção representa um avanço diante da perspectiva reducionista que tem sido dominante na psicologia, fundamentada nas ideias de Piaget e Kohlberg, e que considera os valores a partir do campo específico do desenvolvimento cognitivo, desconsiderando suas ligações com o campo afetivo.

Nessa linha, Branco (2012) sugere uma abordagem alternativa dos valores formulada a partir da Psicologia Cultural do Desenvolvimento e fundamentada no paradigma cultural e sistêmico. Tal abordagem permite dar conta das complexidades da constituição dos valores ao longo do desenvolvimento humano. Desse modo, sugere a autora, é possível compreender a construção de valores partindo de um quadro abrangente que considera a causalidade múltipla e a interdependência entre os fenômenos psicossociais, caracterizados por permanentes tensões dialéticas entre indivíduo e cultura. Branco (2012) ressalta a centralidade da mediação semiótica para a construção da dimensão moral, pois entende que tal processo possibilita ao ser humano sintetizar novos sentidos, tanto no âmbito da reflexão e cognição quanto no âmbito das emoções e afetos.

Essa perspectiva parte de uma concepção dialógica-semiótica do self como um sistema autocatalítico e autorregulador que orienta a pessoa em direção ao futuro, possibilitando e restringindo a emergência de novos sentidos, exercendo um controle flexível sobre os posicionamentos que a pessoa assume em cada momento (Valsiner, 2002). O self pode, assim, ser tomado como uma instância reguladora da construção dos valores, mediante processos 
complexos envolvendo a integração de diferentes níveis hierárquicos de sentidos, tanto no campo pessoal quanto sociocultural.

A fim de entender como significados pessoais (especialmente valores) tornam-se carregados de emoção e afeto, partimos do modelo teórico construído por Valsiner (2007), da Regulação Semiótica da Experiência Humana. Esse modelo mostra como os processos de emergência da função semiótica funcionam em meio aos campos afetivos na regulação da conduta pessoal. Valsiner (2007) sugere que a experiência humana é semioticamente mediada e os processos psicológicos, tais como o pensamento, afeto, imaginação e ação, conformam uma dimensão complexa e integral - a cultura pessoal. Nessa perspectiva, o nível mais alto da hierarquia de mediação semiótica - os valores - não pode ser facilmente traduzido em categorias verbais, mas orienta as ações e interações da pessoa com o mundo. Isso significa que as nossas relações com os outros, nossos posicionamentos em relação aos outros e a nós mesmos e nossa relação com os acontecimentos do mundo, não são apenas racionais e linguísticos, mas incorporados afetivamente. Esse modelo propõe que a experiência humana é organizada em cinco níveis da regulação afetiva, todos interdependentes e interligados, pertencentes a uma ordem hierárquica. Os cinco níveis são conceituados como tal, na Tabela 1.

Tabela 1

Niveis e regulação afetiva semiótica da experiência humana (adaptado de Valsiner, 2007)

\begin{tabular}{ll}
\hline \multicolumn{1}{c}{ Nível } & \multicolumn{1}{c}{ Características } \\
\hline $\begin{array}{l}\text { Nível 0: } \\
\text { Fisiológico }\end{array}$ & $\begin{array}{l}\text { É o nível de sensações fisiológicas e indiferenciadas da consciência que está presente em todas } \\
\text { as espécies animais, e não é específico dos seres humanos. }\end{array}$ \\
\hline $\begin{array}{l}\text { Nível 1: } \\
\text { Sentimento imediato } \\
\text { pré-semiótico }\end{array}$ & $\begin{array}{l}\text { Sentimentos imediatos, sem mediação semiótica, sentimentos pré-verbais que permitem aos } \\
\text { organismos manter as experiências anteriores para uso posterior. Eles não necessitam de } \\
\text { codificação da experiência através de sinais. Memória episódica. }\end{array}$ \\
\hline $\begin{array}{l}\text { Level 2: } \\
\text { Categorias específicas de emoção }\end{array}$ & $\begin{array}{l}\text { Transição para a mediação semiótica. As emoções são nomeadas e experimentadas pela pessoa. } \\
\text { Esse nível é específico para os seres humanos e está articulado verbalmente. }\end{array}$ \\
\hline $\begin{array}{l}\text { Nível 3: } \\
\text { Categorias generalizadas de emoção }\end{array}$ & $\begin{array}{l}\text { Descrição geral das emoções através de um sistema cognitivo. A pessoa chega a uma definição } \\
\text { generalizada pouco específica de suas emoções. Por exemplo: "Eu me sinto mal". }\end{array}$ \\
\hline $\begin{array}{l}\text { Nível 4: } \\
\text { Campos afetivo-semióticos } \\
\text { hipergeneralizados }\end{array}$ & $\begin{array}{l}\text { Os sentimentos mediados emergem sob a forma de campos generalizados - e não em forma } \\
\text { de categorias definidas - devido à abstração. Esse tipo de campo afetivo é hierarquicamente } \\
\text { superior, pois é capaz de exercer regulação sobre outros níveis de regulação da experiência } \\
\text { e orientação da conduta humana. Tais campos podem se transformar no que chamamos } \\
\text { de valores. Por exemplo, honestidade e ética no trabalho, ou sentimentos estéticos como o } \\
\text { sentimento de beleza que envolve uma pessoa que está contemplando uma pintura, são bons } \\
\text { exemplos desse nível. Sua intensidade tem o poder de absorver o pensamento e o sentimento } \\
\text { da pessoa, e ainda assim eles são compartilhados e incorporados em significados coletivos que } \\
\text { são relevantes para a comunidade. }\end{array}$ \\
\hline
\end{tabular}

Na Tabela 1, no nível mais baixo (nível 0), encontram-se os eventos fisiológicos e seus efeitos sobre a dimensão complexa psico-corporal do indivíduo. No próximo nível (Nível 1), observam-se sentimentos afetivos gerais que são imediatos e pré-verbais. No nível 2, há o fluxo de emoções categorizadas, como raiva, tristeza, alegria ou desgosto. No nível 3, a pessoa começa a generalizar o que ele/ela está realmente sentindo, tem dificuldades para descrever tais sentimentos e usar categorias mais amplas. Por fim, no nível mais elevado (Nível 4), alcançamos os campos afetivos semióticos hipergeneralizados que podem ser inferidos, mas são difíceis de definir tanto pela própria pessoa que os experimenta quanto por um observador. Devido à sua qualidade difusa, esses campos afetivos resistem às tentativas mais verbais de descrição precisa. No nível 4, podemos encontrar signos hipergeneralizados, tais como os valores humanos, que orientam a conduta da pessoa, mas eles só podem ser inferidos a partir das ações e das interações das pessoas com seus contextos culturais. O nível 4 é o domínio das experiências afetivas, das quais os valores constituem um bom exemplo.

Os valores são concebidos como construções dinâmicas motivacionais mais elevadas, que são poderosas 0 suficiente para guiar nossa conduta e que estão profundamente imbricadas de afeto. Seu significado psicológico não pode ser descrito com palavras. Em nossa opinião, o modelo de regulação semiótica proposto por Valsiner (2007) reflete a organização hierárquica do sistema motivacional da pessoa. Ele fornece os meios para entender como os valores são forjados, distanciando-se da noção de valor como "traço" ou com aspecto "disposicional", porque enfatiza a 
natureza afetiva-semiótica dos sentidos criados para mediar a experiência humana no mundo.

Branco e Valsiner (2012) apontam que a integração hierárquica de valores e de orientações pessoais funciona como um sistema aberto que muda constantemente. No entanto, ao longo do tempo, alguns valores podem permanecer e se tornar dominantes sobre outros (ou não), dependendo do seu poder regulador sobre o sistema e, também, de fatores como as experiências que a pessoa tem no contexto.

$\mathrm{O}$ presente estudo explora a ideia de que a integração de valores é um processo especialmente relevante durante a transição para a vida adulta, visto que neste momento a pessoa se defronta com valores e crenças pertencentes a novas esferas da experiência e pode começar a questionar valores anteriormente assumidos ou idealizados. Conforme sugerem Branco e Madureira (2008), valores subjetivos altamente relevantes parecem fornecer relativa estabilidade e continuidade neste momento da vida no qual ocorrem transformações significativas no sistema do self. Em recente estudo realizado pelas autoras, os valores se constituíram como um campo extremamente relevante para regulação das mudanças subjetivas operadas por uma jovem homossexual. O estudo mostrou que os posicionamentos assumidos pela jovem estavam associados a valores ambivalentes construídos a partir de sua participação em diferentes esferas da experiência (comunidade religiosa e comunidade gay). Além disso, o estudo revelou ainda que a combinação de valores e posicionamentos foi fundamental para a construção de uma síntese pessoal única, que serviu para orientar as ações da jovem e suas perspectivas futuras. O processo foi permeado pelas contradições emergentes nos posicionamentos assumidos pela jovem, refletindo as dificuldades que ela tinha em identificar-se plenamente com a comunidade gay à qual pertencia.

A perspectiva elaborada aqui compreende que, embora as transições da juventude venham sendo tradicionalmente associadas a marcadores institucionais e estruturais de desenvolvimento, enfatizando uma sequência de eventos que levam à entrada dos jovens no mundo adulto (Camarano, 2004; Elder, 1998), é necessário enfatizar os processos que ocorrem nesse período da vida (Carugati, 2004; Zittoun, 2006, 2007). Entretanto, acreditamos que tais processos ainda necessitam ser mais bem compreendidos e abordados por pesquisas empíricas.

Um dos processos ainda pouco explorados academicamente é a formação dos valores no período da juventude. No entanto, a perspectiva aqui adotada considera tal processo como um dos eixos fundamentais desse período da vida no qual a pessoa participa em novas esferas da experiência e busca integrar novos sentidos de si e do mundo. Nesse período, a emergência da novidade envolve a reconfiguração do sistema do self. "Ser jovem", portanto, implica em processos subjetivos que levam a pessoa a procurar a continuidade de si, em meio às mudanças e às transformações. A formação dos valores é um desses processos subjetivos que tem papel relevante na reorganização da experiência do jovem, bem como de suas relações com os contextos em que transita cotidianamente (Branco \& Madureira, 2008; Branco \& Valsiner, 2012). Esses processos envolvem diretamente as mediações semióticas por meio das quais tanto a pessoa jovem quanto a cultura na qual ela habita são mutuamente constituídos, operando por meio da autorregulação afetiva-dialógica-semiótica (Branco \& Valsiner, 2012).

O presente estudo assume a centralidade dos processos de autorregulação para a integração entre as diversas esferas da experiência de vida ao longo do tempo e tem na construção de um sistema de valores um dos seus eixos fundamentais. O processo é mediado por relações dialógicas com outros sociais significativos, que atuam como catalisadores de tais processos. Encontros dialógicos com outros significativos, localizados em diversas esferas da vida, tornam-se progressivamente internalizados. Outros socais orientam e, também, legitimam a emergência de signos que adquirem a função de promotores do desenvolvimento, pois canalizam o desenvolvimento da pessoa jovem para uma determinada direção.

Processos catalisadores criam "diferenciações emergentes" (Cabell, 2010) em pontos de bifurcação na trajetória de desenvolvimento. Através de processos catalisadores, alguns signos podem surgir no campo do self e agir como promotores ou inibidores do desenvolvimento (Valsiner \& Cabell, 2012). Quando a pessoa jovem enfrenta descontinuidade no seu sistema do self, os signos promotores permitem que ela se distancie da experiência aqui-e-agora e construa pontes de sentido entre passado e futuro, ou entre diferentes esferas de experiência, promovendo a continuidade do sistema do self através do tempo e de diferentes espaços. Assumimos que tais processos autorreguladores são fundamentais para a construção e consolidação de um sistema de valores da pessoa em desenvolvimento.

A Teoria do Self Dialógico (TSD) e seus desdobramentos recentes (Hermans \& Hermans-Konopka, 2010; Salgado \& Gonçalves, 2007) também são relevantes para a compreensão que pretendemos elaborar aqui acerca das transformações que ocorrem no campo do self e, especialmente, para a construção e consolidação de um sistema hierárquico de valores como um dos eixos organizadores da experiência de "ser jovem". De acordo com a TSD, o self é visto como complexo e multifacetado, dotado de múltiplas vozes e posições diferentes que coexistem e mantêm diferentes perspectivas sobre o mundo (Hermans, 2001; Ribeiro \& Gonçalves, 2010; Salgado \& Gonçalves, 2007).

O self é social e emerge através de encontros relacionais com alteridades múltiplas em diferentes esferas da experiência. Encontros dialógicos com múltiplos "outros" sociais tornam-se progressivamente internalizados na forma de posicionamentos (I-Positions). Nesse sentido, o self torna-se um "espaço" privilegiado de negociações eu-outro, que são mais do que apenas negociações de papéis sociais (papéis socialmente esperados). Referem-se também aos significados reflexivos e estados afetivos (Hermans, 2001). Portanto, o self pode ser visto como um sistema de posicionamentos, uma estrutura emergente em um campo 
de possíveis sentidos alternativos de si mesmo e do mundo, tornando-se um espaço por excelência de negociação de valores e crenças predominantes em diferentes esferas da experiência.

\section{A relevância da noção de "responsabilidade"}

Alguns estudos realizados com adolescentes e jovens brasileiros vêm apontando que a responsabilidade, mais especificamente o aumento da responsabilidade, emerge como uma mudança fundamental que ocorre no final da adolescência (Ozella \& Aguiar, 2008). Os autores mostram que esse aumento da responsabilidade, para muitos adolescentes e jovens, vem associado à perda de situações prazerosas, à necessidade de trabalhar para ajudar a família, à preocupação em relação ao futuro (por exemplo, com a possibilidade de não ter emprego) (Oliveira, Pinto \& Souza, 2003) e à necessidade de estudar com mais afinco e compromisso (Ozella \& Aguiar, 2008; Mattos \& Chaves, 2006, 2010). Outros estudos destacam ainda o aumento da responsabilidade no final da adolescência associado a situações ou transições não normativas, tais como a gravidez na adolescência (Cabral, 2003; Dias \& Teixeira, 2010). Esses estudos destacam os diversos significados que a noção de responsabilidade pode assumir, variando muito com a classe, gênero, raça e idade dos adolescentes e jovens pesquisados.

No âmbito internacional, Zittoun (2006, 2007), em seu estudo sobre as transições dos jovens para a vida adulta, sugere a centralidade da construção da responsabilidade simbólica como marcador da experiência dos jovens. A autora defende que se trata de uma construção fundamental que organiza o sistema de valores e a perspectiva de tempo nesse momento da vida. No entanto, Zittoun (2007) compreende a responsabilidade como sendo uma capacidade que o jovem deve desenvolver nessa etapa da vida para "assumir suas próprias internalizações e externalizações simbólicas" (p. 198). A autora argumenta que, ao se defrontar com um mundo no qual não existe um único sistema simbólico capaz de organizar o conjunto dos valores e crenças da pessoa, o jovem tem que fazer uma "colagem" (ou "bricolagem") com os elementos/recursos que estão disponíveis em seu contexto. Assim, ele vai construindo seu sistema de orientação pessoal buscando formas que sejam adaptativas para a vida em sociedade. Diante dessa situação, Zittoun (2007) propõe que o jovem seja "chamado" a assumir sua conduta simbólica, pois a sociedade espera que nesse período da vida ele se torne capaz de assumir as consequências - positivas ou negativas - de suas internalizações e externalizações.

Entretanto, embora a perspectiva apontada por Zittoun $(2006,2007)$ seja relevante, ela não aborda diretamente a questão da responsabilidade como um "valor", mas como uma "capacidade simbólica" individual. Acreditamos, contudo, ser mais apropriado tratar a responsabilidade não como uma "capacidade" conforme propõe a autora, mas como um valor fundamental (Rosa \& González, 2012) que está presente na cultura coletiva e emerge ou que se consolida nesse período da vida. Acreditamos que, ao se defrontar com novas esferas da experiência, é com os valores presentes nesses espaços que o jovem deve se confrontar.

Nas sociedades nas quais vigora o modelo econômico-social do liberalismo, a liberdade é que ganha maior destaque e assume importância central, sendo vista como valor último a ser buscado, defendido e garantido na sociedade. Nesse contexto, a juventude é pensada como uma etapa da vida em que o indivíduo pode "viver mais livremente", pois ainda não tem compromissos sociais com trabalho ou família, ou seja, ainda não precisa assumir "responsabilidades" mais duradouras e permanentes. Contudo, essa visão de juventude, associa-se mais fortemente com a experiência de uma pequena parcela - mais privilegiada - da população, com a experiência dos jovens a quem são dadas oportunidades de viver com mais liberdade. Nesse contexto, os jovens podem exercitar a liberdade de escolha em momentos que serão decisivos para a sua vida futura (escolha da profissão, do parceiro amoroso, de sua "identidade" estética). Embora marcada por matizes ideológicos, essa apreensão social da juventude serve para ilustrar o valor da liberdade como um dos mais relevantes a serem construídos e conquistados nesse período da vida (Mattos \& Castro, 2016).

Nossa perspectiva, entretanto, é de que, na nossa cultura, a liberdade tem como corolário a responsabilidade. Ambos os valores podem ser considerados como duas faces da mesma moeda, pois não existe liberdade sem responsabilidade. Para ter liberdade, para ter autonomia, é preciso ter responsabilidade. Privilegiar somente o exercício da liberdade implica em minimizar a dimensão conflitual do seu exercício cotidiano, camuflando as tensões que emergem e se produzem entre liberdade e responsabilidade. A ideia de liberdade com responsabilidade está, inclusive, muito presente no nosso sistema jurídico, que se organiza em torno da noção de que a pessoa "responde" (civil e penalmente) por seus atos, ou seja, de que é preciso agir com liberdade e com responsabilidade. Na nossa cultura, portanto, os jovens, assim como os adultos, se veem convocados a se subjetivar tendo a liberdade e a responsabilidade como valores que regulam as relações sociais, que pautam tanto desejos e direitos quanto deveres e obrigações.

Nessa linha, é possível supor que o próprio sentido de "responsabilidade" esteja em formação na juventude, emergindo em tensão permanente com o valor da liberdade. Ambos parecem ser fundamentais para organizar o sistema de valores da pessoa em desenvolvimento, possibilitando ao jovem não somente direcionar suas ações presentes e futuras, mas também a lidar com as dificuldades cotidianas e reconfigurar seu sistema de self no sentido de ter mais autonomia.

No presente trabalho, portanto, buscamos aprofundar a compreensão de como a pessoa jovem constrói o sentido "responsabilidade" enquanto um valor fundamental que vai orientar e regular sua conduta, construindo uma 
síntese pessoal na qual ela se percebe como capaz de atuações morais, capaz de ter autonomia com responsabilidade (Branco, 2012; Rosa \& González, 2012). Pois o sentido da "responsabilidade" enquanto um valor fundamental parece estar sendo construído através das mediações semióticas elaboradas nesse momento da vida, a partir das interações dos jovens com novas esferas da experiência e com os outros sociais presentes nesses espaços. Nesses momentos, alguns valores emergentes podem ser conflitantes com valores anteriormente adotados, demandando intensas negociações e novos posicionamentos por parte dos jovens.

Nossa ideia é mostrar como o jovem opera essa dinâmica de construção de si mesmo, de desenvolvimento do self, associado ao campo dos valores, transpondo para o plano intrapessoal (da cultura pessoal) a dinâmica interpessoal (sociocultural) envolvendo a construção de sentidos carregados de afeto. De acordo com Branco, Palmieri e Pinto (2012), tal processo possibilita que alguns sentidos específicos - como o sentido de "responsabilidade" que focalizamos aqui - alcancem mais estabilidade ao longo do tempo e possam garantir continuidade ontogenética no campo do self, servindo para orientar as ações presentes e futuras da pessoa em desenvolvimento.

Quando os jovens se defrontam com novas esferas de experiência, questionam o que assumem como tácito, ou seja, os valores e práticas já construídos anteriormente a partir das relações com outros significativos presentes em esferas centrais da experiência (tais como a família e a escola). Ou seja, ocorre aí um confronto entre sistemas de valores antigos e novos, que são (re)negociados e promovem uma reconfiguração no sistema do self (Gillespie, Cornish, Aveling \& Zittoun, 2007).

Nosso estudo sugere que por meio desse processo a pessoa cria novos conjuntos semióticos que adquirem certa estabilidade ao longo do tempo, passando a organizar e (re)estruturar sua trajetória de vida, "costurando" ou "entrelaçando" o passado e o futuro no presente. Nosso foco, aqui, é explorar como opera o mecanismo de autorregulação ao longo do tempo, mostrando que ele atua de maneira fundamental na experiência de "ser jovem", na construção de uma hierarquia de valores que vai orientar suas ações, pensamentos e sentimentos. Dessa forma, pretendemos explicitar os processos pelos quais os jovens enfrentam os desafios que se colocam quando transitam em diferentes esferas da experiência - incluindo não somente a família e a escola, mas também o trabalho, grupos religiosos e grupos de lazer - e constroem e reconstroem semioticamente a si mesmos, reconfigurando seu sistema de self em torno de um sistema de valores que orienta suas trajetórias de vida.

\section{Metodologia}

O presente estudo foi parte de uma pesquisa qualitativa longitudinal de estudo de casos múltiplos (Stake, 2005). A pesquisa foi estruturada em três rodadas de entrevistas em profundidade e levantou narrativas relativas às trajetórias de vida de seis jovens participantes de um programa de aprendizagem em Salvador (Bahia) durante período compreendido entre os 15 e os 23 anos de idade. Durante a primeira rodada de entrevistas, os jovens estavam com 18-19 anos de idade e narraram suas experiências dos 15 aos 18 anos, quando participaram do programa. Na segunda rodada, estavam com 20-21 anos e narraram suas experiências logo após o término do programa. Na última rodada, com 22-23 anos, os jovens narraram suas experiências um ano e meio após deixarem o programa. Neste artigo relatamos o caso de Jane partindo das narrativas de suas experiências entre 15 e 21 anos de idade. Entrevistas foram realizadas na sede da ONG, em Salvador, na qual o programa de aprendizagem foi desenvolvido e tiveram, cada uma, duração aproximada de duas horas. As entrevistas foram gravadas em áudio e posteriormente transcritas.

\section{Estudo do caso}

Nesta parte do artigo, vamos analisar como a jovem Jane elabora uma nova versão de si mesma em torno da noção de "responsabilidade" enquanto navega entre os campos de significado antigos e novos, assumindo novas posições em diferentes esferas (família e trabalho) para tentar superar desafios e incertezas, construindo uma nova versão de si mesma e de seu futuro no período entre os 16 e 23 anos de idade. O caso da jovem exemplifica a abordagem semiótica-dialógica de construção do sistema de valores, enfatizando a reconfiguração do sistema do self mediante processos de autorregulação e negociações de novos posicionamentos de si em diferentes esferas de experiência, ao longo do tempo. Após a apresentação do caso, buscaremos articular a análise com perspectivas teóricas.

\section{Primeira entrevista: "Eu não vou ser capaz de dar conta disso tudo"}

Na primeira entrevista, Jane nos contou sobre as rupturas que sua família estava passando depois que o pai foi gravemente ferido em um acidente de trabalho e teve que parar de trabalhar por um tempo. Jane tinha 16 anos de idade quando entrou no Programa de Aprendizagem, desenvolvido por uma ONG, e começou a trabalhar na biblioteca de uma universidade particular. Jane pensou que esse era um ponto de bifurcação em sua vida, porque a sobrevivência de sua família dependia quase que exclusivamente em seus ganhos como aprendiz e da ajuda de sua avó (que era dona da casa em que sua família morava).

No início do estudo, quando Jane entrou no ambiente de trabalho como aprendiz, enfrentou um momento crítico e sentiu-se discriminada por seus colegas de trabalho. Ela contou que não confiava em sua própria capacidade para assumir as várias tarefas e responsabilidades de seu trabalho e, além disso, percebeu que ser uma "jovem aprendiz" não era uma posição muito valorizada na empresa. Jane revelou que: 
As pessoas [os colegas] faziam uma distinção porque eu era aprendiz. Eles não me tratavam realmente como uma funcionária da empresa. Quando alguém de fora perguntava quem eu era, eles diziam que eu era uma 'jovem aprendiz', não me consideravam como uma funcionária. Quanto a mim, eu pensava que não seria capaz de fazer todo o trabalho que tinha que fazer. (comunicação pessoal)

Quando alguém de fora perguntava quem era Jane, a bibliotecária sempre dizia que ela era uma "jovem aprendiz". Jane não gostava dessa forma de tratamento e sentia-se desvalorizada e discriminada no novo ambiente.

Com o tempo, no entanto, Jane buscou apoio em uma funcionária mais experiente, Helena, que atuava no RH da empresa, e com quem criou um forte vínculo afetivo, passando a tomá-la como uma referência para lidar com situações difíceis. Toda vez que Jane tinha um problema ou dúvida, ela procurava Helena, que lhe encorajava e dava conselhos para superar os desafios. Jane disse que Helena confiava nela mais do que ela confiava em si mesma, pois Helena sempre a incentivava a desempenhar novas tarefas e tentar realizar novas atividades. Através deste relacionamento, Jane foi capaz de construir mais autoconfiança e posicionar-se como uma trabalhadora responsável. Aos pouco, a jovem foi desenvolvendo um sentido de responsabilidade, considerado como:

a capacidade de se comprometer com algo que estou fazendo, de saber que o que estou fazendo era algo importante, algo que está me fazendo crescer, que vai influenciar no meu futuro. (comunicação pessoal)

Depois de algum tempo, Jane começou a assumir mais responsabilidades no trabalho e passou a confiar em suas novas habilidades. Ela foi contratada pela empresa no final do contrato de aprendizagem e assumiu uma nova função, executando tarefas cada vez mais complexas. A partir de então, Jane passou a se ver como "uma daquelas pessoas com mais responsabilidades" (comunicação pessoal) no seu departamento. Ela passou a acreditar em si mesma, que estava fazendo um bom trabalho e a se sentir mais adaptada ao trabalho. Progressivamente, Jane começou a desenvolver um sentido de autonomia e percebeu que tinha se tornado mais independente da influência de adultos. Ela passou a agir com mais liberdade e a "fazer coisas por si mesma", não ficando tão dependente quanto costumava ser dos "conselhos e opiniões dos adultos". Ela parou de fazer o que os "adultos diziam que [ela] deveria fazer". No trabalho, Jane refletiu que podia ver que "as pessoas a procuram para ajudá-las a resolver seus problemas", e começou a sentir que ela "não era apenas responsável por si mesma, mas também pelos outros" (comunicação pessoal).

Enquanto Jane tentava lidar com diferentes significados de ser responsável no ambiente de trabalho, novas tensões surgiram em seu sistema de self. Depois de algum tempo, obteve reconhecimento de outros significativos presentes no ambiente de trabalho e foi capaz de superar as tensões presentes em seu sistema de self, superando seu desconforto e desconfiança em sua própria capacidade de realizar suas atividades no trabalho. Um novo sentimento generalizado de responsabilidade (nível 3) emerge e ela passa a se ver como uma trabalhadora responsável.

Quando estava com 21 anos, Jane nos contou sobre outra ruptura relevante em sua vida familiar. Sua mãe ficou muito doente e ela teve de gerir todas as despesas da casa e assumir as tarefas domésticas que sua mãe costumava fazer. Entretanto, o novo sentido de responsabilidade que ela havia adquirido no trabalho (como trabalhadora responsável) não se transferiu para seu contexto familiar, no qual a nova ruptura ocorreu. A posição de recém-conquistada como trabalhadora responsável e as correspondentes responsabilidades no trabalho não a ajudaram a lidar com os problemas e as dificuldades emergentes em sua vida familiar. Sobre isso, Jane refletiu:

Eu comecei a ter problemas de dinheiro. Eu tinha um monte de dividas em meu cartão de crédito. Tentei gerir o dinheiro na minha família, porque tudo o que eu ganhava eu dava para sustentar minha familia. Eu tive que organizar tudo, e foi um monte de trabalho! E as dividas começaram a aparecer. (comunicação pessoal)

Embora Jane tivesse um emprego estável e fosse quem mais contribuía para o orçamento enquanto tentava organizar as despesas da família, percebeu que não era capaz de realizar essa tarefa de maneira tão satisfatória quanto sua mãe costumava fazer, nem com a mesma competência e responsabilidade que demonstrava em seu ambiente de trabalho. Emergiu grande ambivalência entre os principais posicionamentos que Jane ocupava nas esferas centrais de sua vida. Sua posição como trabalhadora responsável foi confrontada pela sua posição como filha dependente no ambiente familiar, e Jane se sentiu desesperada e ansiosa por não ser capaz de integrar ambas as posições. O que se percebe aqui é um confronto entre o novo valor emergente de responsabilidade (no trabalho) e o valor antigo de dependência no campo da família.

Dessa forma, essa ambivalência cresceu e foi maximizada, e Jane começou a se sentir "desesperada e mergulhada em dividas financeiras". Ela passou a ter pesadelos e desenvolveu sintomas psicossomáticos, como urticária. Durante esse tempo difícil, Jane aproximou-se de sua avó, uma líder religiosa ${ }^{1}$ em sua comunidade, que também exercia forte influência em sua família. Jane passou a visitar com frequência sua avó no templo religioso e a tomar parte nas cerimônias religiosas, embora não participasse formalmente desse grupo. Aos poucos, Jane começou a se posicionar e a ser posicionada pela comunidade religiosa como uma

1 A avó de Jane era uma mãe-de-santo, isso é, uma sacerdotisa da religião afro-brasileira do candomblé. 
iniciada, aprendendo princípios religiosos, valores e, também, começando a executar algumas tarefas de preparação de rituais, como limpar o templo e cozinhar. Como explicou Jane, como uma iniciada ela teria que "assumir a responsabilidade, não só em relação a [si] própria, mas também para com os outros", tal como sua avó fazia, ou seja, assumir uma espécie de responsabilidade espiritual para o bem-estar das pessoas que faziam parte dessa comunidade.

Com o passar do tempo, Jane contou que uma mudança significativa havia acontecido em sua vida naquele momento: ela havia se "tornado mais responsável" e "aprendido a organizar [suas] finanças". Ela estava lidando com as finanças de forma mais competente, pois havia liquidado todas as dívidas, cortado seus cartões de crédito e pagava tudo com dinheiro (não usava mais os cartões). Jane começou a contabilizar todos seus gastos, tomando notas sobre tudo o que estava pagando, limitando suas despesas ao máximo e comprando apenas o que realmente precisava. Enfim, tinha aprendido a se controlar e começado a "fazer tudo da maneira certa".

Falando sobre outras mudanças que aconteceram em sua vida, Jane também comentou que estava controlando mais sua impulsividade para com os outros. Ela tinha aprendido a lidar melhor com as outras pessoas, a ouvir o que elas tinham a dizer, indicando que estava mais calma e "não entrava mais em disputa com outros por coisas pequenas". Ela aprendeu a ter mais controle sobre suas atitudes e comportamentos.

Refletindo sobre as mudanças em sua vida, Jane revelou que se sentia agora como uma pessoa adulta, porque podia "assumir sua vida por si mesma agora" e era capaz de "dizer o que queria e o que não queria, o que podia e o que não podia fazer". Jane refletiu que ela podia agora "tomar conta da [sua] própria vida", pois agora ela era "responsável não só por [si] própria, mas também pelos outros". Comentando sobre o que ela considerava ser uma pessoa adulta, Jane refletiu que

Aprendi a administrar meu dinheiro. Paguei todas as minhas dividas. Cortei todos os meus cartões de crédito. ... Eu acho que eu posso cuidar de minha própria vida agora. Eu não sou responsável apenas por mim mesma, eu sou responsável por outros também, por ajudar os outros, sentindo que não só a minha própria vida depende de mim, mas a vida dos outros também pode depender de mim. (comunicação pessoal)

Durante essa terceira entrevista, Jane observou que, ao longo do tempo, desenvolveu um novo sentido de si mesma e do mundo a sua volta. Ela revelou uma nova configuração do seu sistema de self, integrando as posições relevantes no campo do trabalho e da família, com o apoio de adultos significativos, como sua avó. Ela aprendeu como administrar o dinheiro da família e se sentiu mais responsável, tanto em relação a si mesma quanto em relação aos outros.
Pode-se perceber que um novo sentido de responsabilidade emergiu no campo do self de Jane: um sentido hipergeneralizado de responsabilidade. Nessa linha, compreende-se que um novo valor emergiu no campo do self de Jane - a responsabilidade espiritual (nível 4) - e começou a orientar suas experiências de vida em diferentes esferas da vida. É possível conceber que através do movimento de produção de novos sentidos no campo do self, em suas interações com o campo do trabalho e com o contexto familiar, Jane foi construindo um sistema de valores que passou a orientar suas ações no presente e em relação ao futuro.

Jane também relatou ter "planos para [sua própria] vida", e que ela queria "ter um lugar [um espaço] que fosse [dela] própria". Ela nos disse que agora podia sonhar com o futuro, que estava "buscando ser feliz".

A trajetória de Jane mostra como emergem, ao longo do tempo, os processos de autorregulação semiótica, surgindo a partir das interações dialógicas com outros significativos, presentes em diferentes esferas de experiência. Tal processo leva não somente à dinâmica de posicionamentos e reposicionamentos dentro do próprio sistema do self, mas igualmente às transformações de valores - e mais especificamente ao valor da "responsabilidade". O caso de Jane ilustra os mecanismos que operam a construção semiótica de um sistema de hierárquico de valores na transição da jovem para a vida adulta, no qual o valor da "responsabilidade" assume um lugar central. Ele mostra como se superam as tensões dialógicas e revela a dinâmica dos movimentos de posicionamentos e reposicionamentos no interior do self dialógico através do tempo e entre diferentes espaços ou esferas da experiência da vida da jovem.

$\mathrm{Na}$ linha de uma abordagem dialógica-semiótica do self, é possível compreender a interação complexa entre as posições de Jane como uma tentativa de superar a ambivalência. Para lidar com as ambivalências emergentes em diferentes contextos, Jane constrói novos sentidos para orientar suas experiências e faz uma hierarquia de sentidos carregados de afeto, relacionados com a noção de responsabilidade, os quais podem trazer certa estabilidade para o self dela ao longo do tempo.

Conforme ilustra a Figura 1, a versão inicial do self de Jane (A) entra na esfera do trabalho e inicia uma relação dialógica com Helena (B), que reconhece antecipadamente a competência dela para realizar com êxito suas tarefas no campo do trabalho (mesmo antes dela reconhecer esse potencial em si mesma). Jane começou a internalizar a voz de Helena e desenvolveu uma posição promotora como trabalhadora-responsável (C). Algum tempo depois, ao defrontar-se com novos desafios na sua vida familiar - a doença da mãe - e através de relações dialógicas com sua mãe doente (B'), Jane posiciona-se como administradora-irresponsável-de-dinheiro (C'), e não é capaz de aplicar o tipo de responsabilidade que desenvolveu no campo do trabalho em suas tarefas na família. Os dois posicionamentos como trabalhadora-responsável e como administradora-irresponsável-de-dinheiro são poderosos e dominam o cenário 
das relações dialógicas nas principais esferas da vida de Jane - família e trabalho. No entanto, há uma crescente tensão entre essas duas posições dominantes porque se referem a formas contraditórias de lidar com a responsabilidade.

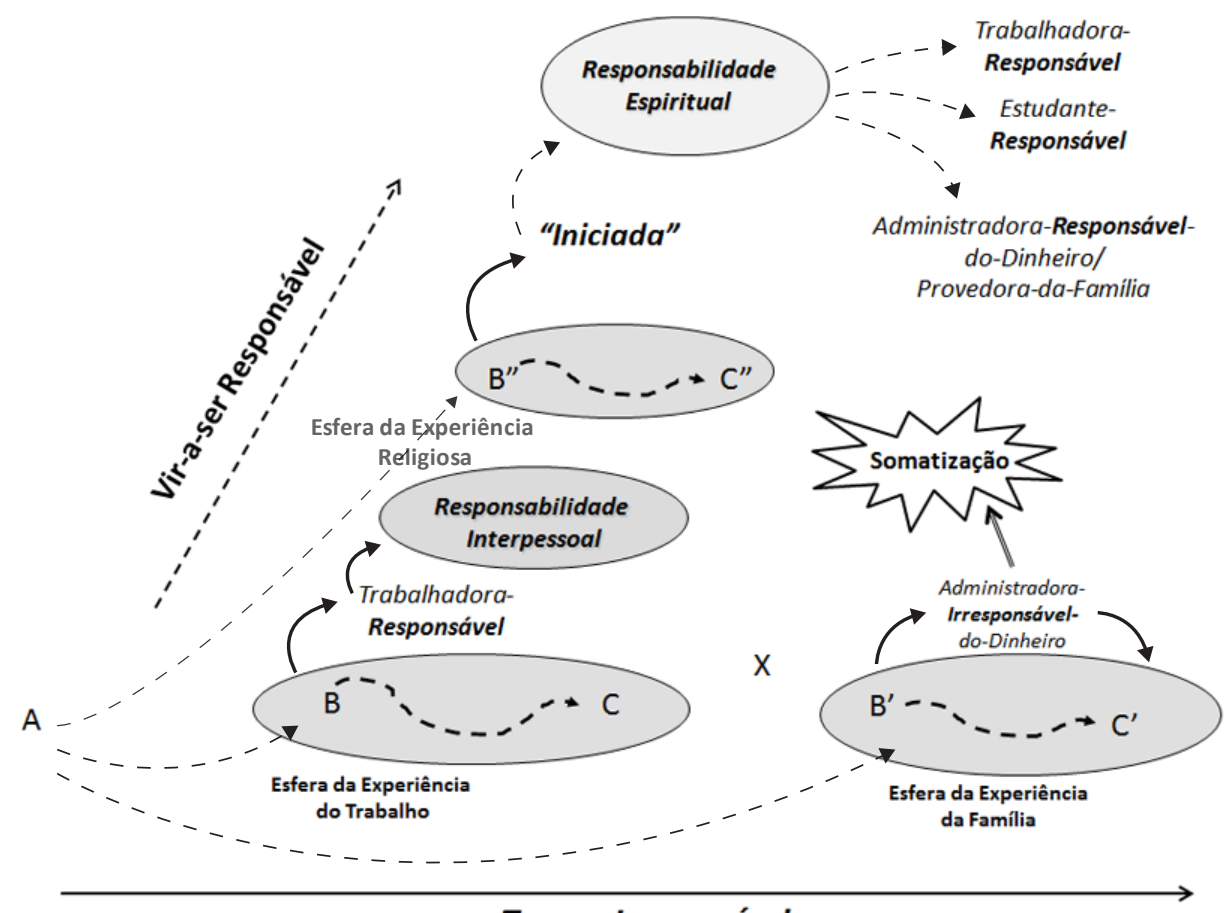

Tempo Irreversível

Figura 1. Autorregulação através da diferenciação hierárquica da "responsabilidade"

Buscando superar a ambivalência, Jane constrói novos sentidos, aumentando sua participação na esfera religiosa e aproximando-se da figura poderosa de sua avó (B"), que oferece uma visão antecipada de Jane no futuro, projetando-a em algo que ela não é ainda, mas pode tornar-se: uma pessoa capaz de assumir um nível mais alto de responsabilidades, fazendo aquilo que sua avó fazia. As relações dialógicas de Jane com a avó (B”) levam ao desenvolvimento de uma nova posição empoderada - iniciada (C") -, que se caracteriza por uma perspectiva ampliada acerca da responsabilidade: a responsabilidade espiritual. Esse novo sentido mais amplo de "responsabilidade" atua como um valor poderoso que integra diferentes esferas da vida de Jane (trabalho, família, religião) e favorece a continuidade (passado-presente-futuro) ao tempo em que a cultura valorizada pela família funde-se com a cultura pessoal de Jane pelo significado da religiosidade.

Através dos dados, pode-se encontrar o papel desempenhado pelo sistema de valores no desenvolvimento do self de Jane, dotando o self de relativa estabilidade e favorecendo uma integração entre diferentes esferas da vida ao longo do tempo, o que resulta em uma reconfiguração de sistema do self no espaço e no tempo. A intervenção da poderosa posição como iniciada - emergente na esfera religiosa - é capaz de unir, de costurar, sentidos parciais e/ou limitados de "responsabilidade" que emergem em domínios específicos da vida, proporcionando uma continuidade do self em diferentes contextos. Nesse momento, Jane torna-se capaz de colocar todas as formas limite de "responsabilidades" em perspectiva, e amplia sua noção de responsabilidade para diferentes esferas da vida. Ela se torna mais responsável através dos contextos de trabalho, família e religião.

O posicionamento como iniciada traz um sentido de responsabilidade espiritual que emerge como uma versão do self poderosa e carregada de afeto, capaz de entrelaçar (i.e. "costurar") diferentes sentidos de responsabilidade presentes nas demais esferas da vida de Jane. Por um lado, a jovem pôde redefinir o sentido da responsabilidade pessoal que ela construiu na esfera do trabalho através de trocas dialógicas com Helena, tornando Jane capaz de assumir novas funções de trabalho e de ajudar os colegas nas tarefas deles. Por outro lado, também redefiniu suas responsabilidades interpessoais no âmbito da família e tornou-se responsável não só por si mesma, mas também pelos outros, isto é, por seus pais e por sua irmã. Passou a ser mais organizada com as despesas, invertendo papéis e responsabilidades com a mãe, assumindo as funções que originalmente pertenciam a sua mãe. Jane torna-se capaz de autorregular seus pensamentos, ações e sentimentos por meio da criação de um signo promotor que produz pontes de sentido entre diferentes esferas da experiência, entrelaçando (isto é, "costurando") diferentes sentidos de responsabilidade.

Os ciclos recorrentes de produção de novos sentidos mostram que, a fim de superar tensões e ambivalências, Jane tem de criar signos em um nível mais alto de generalização na hierarquia semiótica, tais como "responsabilidade 
interpessoal" e "responsabilidade espiritual". Esses signos carregados de afetos representam conjuntos de sentidos e valores específicos. A superação da incerteza emerge da construção de pontes de sentido, criadas no momento em que Jane se lança na busca por signos hipergeneralizados capazes de atuar como promotores do seu desenvolvimento e integrar múltiplas esferas de experiência. Esse movimento projeta uma nova trajetória de vida para Jane, orientada pelo valor da "responsabilidade" - um valor abrangente que é capaz de integrar e, simultaneamente, de transcender os diversos campos da experiência nos quais ela está inserida.

\section{Considerações finais}

Neste artigo, buscamos explorar a centralidade da mediação semiótica na experiência dos jovens, focalizando no movimento por meio do qual a jovem Jane reconfigurou seu sistema de self e, simultaneamente, construiu e consolidou um sistema de valores capaz de organizar suas relações com diversas esferas da experiência e de direcionar suas ações futuras. Sugerimos que os posicionamentos e reposicionamentos que a jovem foi assumindo em momentos específicos, a partir de interações dialógicas com outros sociais em diversos contextos, possibilitaram a emergência de signos promotores através de processos catalíticos, resultando na construção de uma trajetória de vida orientada pelo valor da "reponsabilidade". A jovem construiu uma nova configuração do sistema do self e moldou seu futuro em meio a um processo de autorregulação semiótica.

Buscamos compreender a juventude não como uma etapa universal de desenvolvimento, mas a partir de processos psicológicos e sociais de transição entre a infância e a fase adulta e que dependem das circunstâncias sociais e históricas para a formação do sujeito. Nessa linha, ressaltamos que o movimento de construção de um sistema de valores, sobretudo aqueles associados ao binômio liberdade-responsabilidade, parece ser um dos eixos fundamentais da experiência de "ser jovem" na nossa cultura. Em especial, ganha relevância a construção do valor da "responsabilidade", que assume um papel central nesse momento da vida em que a pessoa passa a interagir com novos sistemas de valores, presentes nos novos espaços em que começa a transitar (sobretudo na esfera do trabalho). É um movimento que ganha cada vez mais relevância em sociedades como a nossa, nas quais vigora o modelo econômico-social do liberalismo, especialmente entre jovens de classes menos favorecidas, contribuindo para romper com uma visão idealizada da juventude como uma etapa em que o indivíduo pode "viver mais livremente".

Esse movimento coloca em xeque não somente uma visão idealizada da juventude, mas faz que o jovem, em suas relações cotidianas, passe a questionar valores tradicionais que, anteriormente, orientavam sua conduta. No caso apresentado, as ambivalências emergentes, então, fizeram que Jane se lançasse em ciclos de produção de novos sentidos, capazes de integrar valores conflitantes. Uma nova sintese pessoal emergiu quando Jane internalizou criativamente signos hipergeneralizados carregados de afeto e localizados em niveis mais altos da hierarquia semiótica, dando um novo rumo a sua trajetória. Nesse sentido, conforme sugerem Branco e Valsiner (2012), o valor da responsabilidade foi construído por mediações semióticas em interações com outros, ganhando relevância na construção da cultura pessoal e passando a orientar a conduta de Jane.

Esses processos atuaram como mecanismo central na construção do sistema de valores que orienta a cultura pessoal de Jane, servindo para ativar os ciclos de produção de novos sentidos. Sem eles, não seria possível fazer emergir posições promotoras de desenvolvimento (isto é, a posição iniciada). Sendo assim, é possível pensar que, mediante a ativação do ciclo de produção de novos sentidos, o campo do self de Jane sofreu uma transformação significativa e se reconfigurou. Tal processo possibilitou à jovem conceber-se como agente capaz de atuar com autonomia e responsabilidade (Rosa \& González, 2012).

É importante destacar, contudo, que o campo dos valores, pode ser também uma fonte de diversos conflitos na vida do jovem, e não apenas um elemento de superação de ambivalência por meio do alcance de uma posição integradora hierarquicamente superior, tal como ocorreu no caso de Jane. Os processos de autorregulação presentes nas transições dos jovens, bem como na experiência humana de forma geral, podem tanto promover, facilitar, quanto inibir transformações no sistema do self ao longo do tempo. Especificamente, conforme abordamos em outros trabalhos (Mattos \& Chaves, 2013; Mattos, no prelo), as dinâmicas da subjetivação podem envolver diferentes formas de regulação semiótica que levam tanto à promoção quanto à inibição de processos de mudança no campo do self. Enquanto, por um lado, tal como no caso de Jane, alguns processos $f a-$ cilitam a superação das ambivalências por meio do alcance de uma posição integradora, gerando uma reconfiguração do sistema do self (na direção de produzir uma maior flexibilidade e dialogicidade do sistema), processos inibidores podem bloquear tal reconfiguração e trazer maior rigidez ao sistema do self, dificultando a emergência de sentidos ou posições alternativas, diminuindo a dialogicidade e flexibilidade do sistema. Novas pesquisas sobre autorregulação dos processos subjetivos podem contribuir para esclarecer melhor tais aspectos e ampliar a nossa compreensão sobre como os valores podem servir para facilitar ou inibir mudanças e inovações no campo da experiência.

\section{Semiotics mediation of "responsibility": a study on the construction of values in the transition to adulthood}

Abstract: The construction of values is seen as an intensely dynamic process involving the internalization and externalization of collective meanings, as well as being fundamental to the construction of a personal synthesis. This article starts from the perspectives 
of Cultural Psychology and Dialogic SelfTheory and proposes that "responsibility" can be understood as a value, as a semiotic affective field full of senses. A case study illustrates how a young woman (Jane) navigates on the collective culture and builds a new personal meaning itself as a "responsible person". The value of "responsibility" becomes progressively integrated into her personal values system through continuities and changes in her positions over time and in different spaces, specifically the family, work and religion. The results illustrate the dynamic transformation of positions over time and the emergence of new perspectives for the future.

Keywords: Responsibility, values, transition to adulthood, Dialogical Self Theory.

\section{La médiation sémiotique de la « responsabilité » : une étude sur la construction de valeurs dans la transition vers la vie adulte}

Résumé: La construction de valeurs est considérée comme un processus intensément dynamique impliquant internalisation et externalisation des significations collectives, et est fondamental pour la construction d'une synthèse personnelle. Dés le point de vue de la Psychologie Culturelle et de la Théorie du Soit Dialogique, la «responsabilité» peut être comprise comme une valeur, comme domaine affective sémiotique chargé de sens. Cette étude de cas illustre comment un jeune fille (Jane) circule dans la culture collective et construit une nouvelle signification personnelle d'elle-même comme une "personne responsable». La valeur de la «responsabilité» devient progressivement intégré dans le système de valeurs de Jane à cause des changements dans ses positions au fil du temps et dans divers situations de vie, en particulier la famille, le travail et la religion. Les résultats illustrent la transformation dynamique des positions et l'émergence de nouvelles perspectives pour l'avenir.

Mots-clés: Responsabilité, valeurs, transition à l'âge adulte, Théorie du Self Dialogic.

\section{La mediación semiótica de "responsabilidad": estudio sobre la construcción de valores en la transición para la vida adulta}

Resumen: La construcción de valores es un proceso intensamente dinámico, involucrando internalización y externalización de significados colectivos, y fundamental para la construcción de una síntesis personal. Desde el punto de vista de la Psicología Cultural y de la teoría del Self Dialógico, este artículo se propone a pensar si la "responsabilidad" puede ser entendida como un valor, como un campo afectivo semiótico pleno de sentidos. Un estudio de caso ilustra cómo una joven (Jane) navega en la cultura colectiva y construye un nuevo significado personal de sí misma como una "persona responsable". El valor de la "responsabilidad" se integra progresivamente en el sistema de valores personales de Jane, mientras continuidades y cambios en sus posiciones en el tiempo y en diferentes situaciones, especialmente la familia, el trabajo y la religión. Los resultados ilustran la transformación dinámica de las posiciones y el surgimiento de nuevas perspectivas para el futuro.

Palabras clave: responsabilidad, valores, transición a la edad adulta, teoría del self dialógico.

\section{Referências}

Branco, A. U. (2012). Values and socio-cultural practices: pathways to moral development. In J. Valsiner (Ed.), The Oxford Handbook of culture and psychology (pp. 749766). New York, NY: Oxford University Press.

Branco, A., \& Madureira, A. F. (2008). Dialogical Self in action: the emergence of self-positions among complex and cultural dimensions. Estudios de Psicología, 29(3), 319-332.

Branco, A. U., Palmieri, M., \& Pinto, R. (2012). Cultural practices and value constructions: the development of competition and individualism within societies. In A.U. Branco \& J. Valsiner (Eds.), Cultural psychology of human values (pp. 31-62). Charlotte, NC: Information Age.

Branco, A., \& Valsiner, J. (2012). Cultural psychology of human values. Charlotte, NC: Information Age.
Cabell, K. (2010). Mediators, regulators, and catalyzers: A context-inclusive model of trajectory development. Psychology \& Society, 3(1), 26-41.

Cabral, C. S. (2003). Contracepção e gravidez na adolescência na perspectiva de jovens pais de uma comunidade favelada do Rio de Janeiro. Cadernos de Saúde Pública, 19(2), 283-292.

Camarano, A. A. (2004). Os caminhos dos jovens em direção à vida adulta. Revista do IPEA - Instituto de Pesquisa Econômica Aplicada, 1(1), 59.

Carugati, F. (2004). Learning and thinking in adolescence and youth: how to inhabit new provinces of meaning. In A. N. Perret-Clermont, C. Pontecorvo, L. Resnick, T. Zittoun \& B. Burge (Eds.) Joining society: social interaction and learning in adolescence and youth ( $\mathrm{pp}$. 119-40). New York, NY: Cambridge University Press. 
Dias, A C. G., \& Teixeira, M. A. P. (2010). Gravidez na adolescência: um olhar sobre um fenômeno complexo. Paideia, 20(45), 123-131.

Gillespie, A., Cornish, F., Aveling, E., \& Zittoun, T. (2007). Conflicting community commitments: a dialogical analysis of a British woman's World War II diaries. Journal of Community Psychology, 36(1), 35-52.

Elder, G. (1998). Life course as developmental theory. Child development, 69(1), 1-12.

Hermans, H. J. M. (2001). The dialogical self: toward a theory of personal and cultural positioning. Culture \& Psychology, 7, 243-281.

Hermans, H., \& Hermans-Konopka, A. (2010). Dialogical self theory: positioning and counter-positioning in a globalizing society. New York, NY: Cambridge University Press.

Mattos, E. (2013). Self-development in the transition to adulthood: a longitudinal study with youth from Bahia (Dissertação de mestrado). Universidade Federal da Bahia, Salvador.

Mattos, A. R., \& Castro, L. R. (2016). Jovens e a liberdade: reflexões sobre autonomia, responsabilidade e independência. Psicologia \& Sociedade, 28(1) 65-73.

Mattos, E. (no prelo). The dynamics of self-transformation in youth transitions: the role of promoting and inhibiting processes. In M. Han \& C. Cunha (Eds.), The subjectified and subjectifying mind. Charlotte, NC: Information Age.

Mattos, E., \& Chaves, A. M. (2006). As representações sociais do trabalho entre adolescentes aprendizes: um estudo piloto. Revista Brasileira de Crescimento e Desenvolvimento Humano, 16(3), 66-75.

Mattos, E., \& Chaves, A. M. (2010). Trabalho e escola: é possível conciliar? A perspectiva de jovens aprendizes baianos. Psicologia Ciência e Profissão, 30(3), 540-555.

Mattos, E., \& Chaves, A. M. (2013). Semiotic regulation through inhibitor signs: creating a cycle of rigid meanings. Integrative Psychological and Behavioral Science, 47(1), 95-122.

Oliveira, M. C., Pinto, R. G., \& Souza, A. S. (2003). Perspectivas de futuro entre adolescentes: universidade, trabalho e relacionamentos na transição para a vida adulta. Temas em Psicologia da SBP, 11(1) 16-27.
Ozella, S., \& Aguiar, W. M. J. (2008). Desmistificando a concepção de adolescência. Cadernos de Pesquisa, 38(113), 97-125.

Paolichi, P. (2007). The institutions inside: self, morality, and culture. In J. Valsiner \& A. Rosa (Eds.), The Cambridge handbook of sociocultural psychology (pp. 560-575). New York, NY: Cambridge University Press.

Ribeiro, A. P. \& Gonçalves, M. M. (2011). Maintenance and transformation of problematic self-narratives: A semiotic-dialogical approach. Integrative Psychology and Behavioral Science, 45, 281-303.

Rosa, A., \& González, F. (2012). Values, virtues, citizenship, and self from a historical and cultural approach. In A. U. Branco \& J. Valsiner (Eds.), Cultural psychology of human values (pp. 3-30). Charlotte, NC: Information Age.

Salgado, J., \& Gonçalves, M. M. (2007). The dialogical self: social, personal, and (un)conscious. In J. Valsiner \& A. Rosa (Eds.), The Cambridge handbook of social cultural psychology (pp. 608-621). Cambridge: Cambridge University Press.

Stake, R. E. (2005). Qualitative case studies. In N. K. Denzin \& Y. S. Lincoln (Eds.), The Sage handbook of qualitative research (3rd ed., pp. 433-466). Thousand Oaks, CA: Sage.

Valsiner, J. (2002). Forms of dialogical relations and semiotic autoregulation within the self. Theory \& Psychology, 12(2), 251-265.

Valsiner, J. (2007). Culture in minds and societies. New Delhi: Sage.

Valsiner, J., \& Cabell, K. (2012). Self-Making through synthesis: Extending dialogical self theory. In H. J. M. Hermans \& T. Gieser (Eds.), Handbook of the Dialogical Self (pp. 82-97). NY: Cambridge University Press.

Zittoun, T. (2006) Transitions: development through symbolic resources. Charlotte, NC: Information Age.

Zittoun, T. (2007). Symbolic resources and responsibility in transitions. Young, 15, 193-211.

Recebido: $20 / 01 / 2015$

Revisado: $22 / 03 / 2016$

Aceito: 26/04/2016 